\title{
Smoking Cessation in Cancer Survivors
}

\author{
Young Gyu Cho* \\ Department of Family Medicine, Inje University Seoul Paik Hospital, Inje University College of Medicine, Seoul, Korea
}

\section{See original paper on 281}

Smoking is the main modifiable risk factor of cancer morbidity and mortality. Continuing to smoke after a cancer diagnosis increases the risk of second primary cancer, treatment toxicity and failure, decreased quality of life, and increased overall mortality. ${ }^{1)}$ Smoking cessation can reduce these outcomes. A cancer diagnosis significantly increases motivation to quit smoking and interest in smoking cessation programs. ${ }^{2}$ However, previous studies have revealed that more than $50 \%$ of Korean cancer survivors who smoked at the time of diagnosis continued to smoke. ${ }^{3-5)}$

Since the ratification of the World Health Organization Framework Convention on Tobacco Control in 2005, the Korean government has introduced and strengthened numerous tobacco control policies. For example, in 2015, the retail price for a pack of cigarettes increased from 2,500 to 4,500 Korean won; all restaurants, coffee shops, bars, and so forth became smoke-free; and the National Health Insurance Service started paying the cost of smoking cessation treatment. In 2016, pictorial health warnings were inserted on cigarette packs. ${ }^{6,7)}$ These comprehensive tobacco control policies have been effective in reducing smoking prevalence among Korean male adults (age-standardized prevalence: $48.3 \%$ in $2010,35.7 \%$ in 2019). ${ }^{8,9)}$ However, the effectiveness of these policies in modifying the smoking behavior of Korean cancer survivors has not been researched.

Cheon et al. ${ }^{10)}$ investigated trends in the prevalence of current smoking and willingness to quit among Korean male cancer survivors using data from the Korea National Health and Nutrition Examination Survey (KNHANES), 2010-2017. Out of 20,012 male adults who participated in KNHANES, 2010-2017, 742 men (3.7\%) were cancer survivors. The results of the study revealed the prevalence of current smoking did not change significantly from 2000 to 2017 among cancer sur- vivors ( $\mathrm{P}$ for trend=0.33), although it significantly decreased over the same period in the non-cancer group ( $\mathrm{P}$ for trend $<0.001$ ). The proportion of current smokers who were willing to quit smoking did not present a significant trend in either cancer survivors ( $\mathrm{P}$ for trend $=0.964$ ) or the non-cancer group ( $\mathrm{P}$ for trend=0.884). These findings suggest that the tobacco control policies in Korea, while effective in reducing smoking prevalence in the general population, had only a limited effect on modifying the smoking behavior of cancer survivors. Thus, which strategies might promote smoking cessation for cancer survivors should be identified.

A cancer diagnosis generally increases motivation to quit smoking. However, this increased motivation does not translate into higher quitting rates among cancer survivors as those unable to quit smoking after a diagnosis are more likely to be hardcore smokers with high nicotine dependence. Cancer survivors who continue to smoke perceive that health problems from smoking are less serious, the benefits of quitting for cancer prognosis are lower, and the barriers to quitting are greater. They are also more frequently exposed to others' smoking. ${ }^{11)}$ A cancer diagnosis is stressful for patients, some of whom used smoking to cope with their stress. Many health professionals were hesitant to raise the issue of smoking due to fears that it may exacerbate cancer patients' guilt about smoking and damage therapeutic relationships. Although most medical staff asked whether patients smoked at the initial assessment, only a few advised them to quit smoking. ${ }^{12)}$

Current smoking cessation interventions were reported to be ineffective in promoting cancer survivors to quit smoking. ${ }^{13)} \mathrm{Li}$ et al. ${ }^{14)}$ showed that a brief intervention based on communicating the risk was ineffective in helping cancer patients to quit smoking and they suggested that a comprehensive intervention might be more effective. However, most oncologists note that it is difficult to provide a comprehensive smoking cessation intervention themselves to their patients 
due to a lack of time, training, and resources. They preferred to refer their patients to a trained cessation specialist who could provide an evidence-based smoking cessation program. ${ }^{15-17)}$ Many primary care physicians in Korea, who are trained to provide evidence-based smoking cessation treatment, have participated in the smoking cessation service provided by the National Health Insurance Service. ${ }^{18)}$ It is recommended that well-trained primary care physicians can be used as resources to provide comprehensive smoking cessation intervention to cancer survivors. In addition, a collaborative approach between oncologists and primary care physicians would help to promote smoking cessation for cancer survivors.

\section{CONFLICT OF INTEREST}

No potential conflict of interest relevant to this article was reported.

\section{ORCID}

Young Gyu Cho: https://orcid.org/0000-0003-1017-8884

\section{REFERENCES}

1. Jassem J. Tobacco smoking after diagnosis of cancer: clinical aspects. Transl Lung Cancer Res 2019;8(Suppl 1):S50-8.

2. Gritz ER, Fingeret MC, Vidrine DJ, Lazev AB, Mehta NV, Reece GP. Successes and failures of the teachable moment: smoking cessation in cancer patients. Cancer 2006;106:17-27.

3. Park JJ, Park HA. Prevalence of cigarette smoking among adult cancer survivors in Korea. Yonsei Med J 2015;56:556-62.

4. Kim H, Kim MH, Park YS, Shin JY, Song YM. Factors that predict persistent smoking of cancer survivors. J Korean Med Sci 2015;30:853-9.

5. Koo HY, Lee K, Park SM, Chang J, Kim K, Choi S, et al. Prevalence and predictors of sustained smoking after a cancer diagnosis in Korean men. Cancer Res Treat 2020;52:139-48.

6. Seo HG, Kim Y, Xu SS, Quah AC, Boudreau C, Yan M, et al. Tobacco control policies in the Republic of Korea and the methods of the ITC Korea Surveys. J Korean Soc Res Nicotine Tob 2018;9(Suppl S1):S1-10.

7. Gunter R, Szeto E, Jeong SH, Suh S, Waters AJ. Cigarette smoking in
South Korea: a narrative review. Korean J Fam Med 2020;41:3-13.

8. Kim DJ, Kim SJ. Impact of increased tobacco price on adult smoking rate in South Korea. Health Policy Manag 2017;27:219-28.

9. Korea Disease Control and Prevention Agency. Korea health statistics 2019: Korea National Health and Nutrition Examination Survey (KNHANES VIII-1) [Internet]. Cheongju: Korea Disease Control and Prevention Agency; 2019 [cited 2021 Jul 1]. Available from: https:// knhanes.kdca.go.kr/knhanes/sub04/sub04_04_01.do.

10. Cheon SW, Park SG, Yoo SM, Kim HE, Kim HJ. Trend in prevalence of smoking and motivation to quit among Korean adult male cancer survivors over the last 8 years: the Korea National Health and Nutrition Examination Survey V-VII (2010-2017). Korean J Fam Med 2021;42: 281-7.

11. Lee Westmaas J, Berg CJ, Alcaraz KI, Stein K. Health behavior theory constructs and smoking and cessation-related behavior among survivors of ten cancers nine years after diagnosis: a report from the American Cancer Society's Study of Cancer Survivors-I. Psychooncology 2015;24:1286-94.

12. Wells M, Aitchison P, Harris F, Ozakinci G, Radley A, Bauld L, et al. Barriers and facilitators to smoking cessation in a cancer context: a qualitative study of patient, family and professional views. BMC Cancer 2017;17:348.

13. Sheeran P, Jones K, Avishai A, Symes YR, Abraham C, Miles E, et al. What works in smoking cessation interventions for cancer survivors?: a meta-analysis. Health Psychol 2019;38:855-65.

14. Li WH, Wang MP, Ho KY, Lam KK, Cheung DY, Cheung YT, et al. Helping cancer patients quit smoking using brief advice based on risk communication: a randomized controlled trial. Sci Rep 2018;8:2712.

15. Day FL, Sherwood E, Chen TY, Barbouttis M, Varlow M, Martin J, et al. Oncologist provision of smoking cessation support: a national survey of Australian medical and radiation oncologists. Asia Pac J Clin Oncol 2018;14:431-8.

16. Warren GW, Ward KD. Integration of tobacco cessation services into multidisciplinary lung cancer care: rationale, state of the art, and future directions. Transl Lung Cancer Res 2015;4:339-52.

17. Kaiser EG, Prochaska JJ, Kendra MS. Tobacco cessation in oncology care. Oncology 2018;95:129-37.

18. Paek YJ, Choi JK, Lee ES, Jo MW. Smoking cessation services provided by the National Health Insurance Service. J Korean Med Assoc 2018; 61:157-62. 